\title{
Anti-oxidant and Anti-pollution Composition Containing the Extract of Nypa fruticans Wurmb, Saussurea neoserrata, Codium fragile and Enteromorpha compressa
}

\author{
Go-Eun Choi ${ }^{1, *}$, Gil-Hyun Lee ${ }^{2, *}$ and Kyung-Yae Hyun ${ }^{2, ;, *}$ \\ ${ }^{1}$ Department of Clinical Laboratory Science, Catholic University of Pusan, Busan 46252, Korea \\ ${ }^{2}$ Department of Clinical Laboratory Science, Dong-Eui University, Busan 47340, Korea
}

\begin{abstract}
Long-term exposure to environmental pollutants can impair the human skin's barrier function and promote skin aging mechanisms. The visible consequences of these effects are dryness, wrinkles, black spots and worsening skin sensitivity. As awareness of the effects of environmental stressors on the skin has recently increased, consumers' demand for cosmetics that can provide anti-pollution effects is increasing. In this study, the possibility of anti-pollution cosmetic material was investigated by measuring the inhibitory effect of free radicals using a mixture of Nypa fruticans Wurmb (NF), Saussurea neoserrata (SN), Codium fragile (CF) and Enteromorpha compressa (EC), which has anti-inflammatory and antioxidant effects against irritation caused by dust. Combining the experimental results of a mixture of NF, SN, CF and $\mathrm{EC}$ by induction of fine dust stimulation, inhibition of inflammatory factors $\left(\mathrm{PGE}_{2}\right)$ and intracellular free radicals (ROS) by inhibiting effects were significant, indicating the possibility of use as anti-pollution cosmetics. The most plants used as sources of anti-pollution cosmetic ingredients contain antioxidants as active substances. In our highly industrialized and chemically polluted world, it is not surprising that most plants used as sources of anti-pollution cosmetic ingredients contain antioxidants as active substances. Considering our results, it can be suggested that this anti-pollutant consisting of NF, SN, CF and EC may be a good ingredient for skincare products for the cosmetic industry due to their antioxidant properties, which may especially alter skin aging.
\end{abstract}

Key Words: Particulate matters, Nypa fruticans Wurmb, Saussurea neoserrata, Codium fragile, Enteromorpha compressa, Anti-oxidant, Anti-pollution

\section{INTRODUCTION}

Particulate matters (PM) is a fine dust that floats for a long time in the atmosphere containing numerous pollutants along with sulfur oxides, nitrogen oxides, lead, ozone and carbon monoxide (Pan et al., 2015). PM10 is referred to as respiratory dust with a diameter of $10 \mu \mathrm{m}$ or less, PM2.5 as fine dust with a diameter of $2.5 \mu \mathrm{m}$ or less, and PM1.0 as ultrafine dust with a diameter of $1.0 \mu \mathrm{m}$ or less. Because PM2.5 has a large surface area, it is easy to adsorb harmful metals or gaseous pollutants, and when it is deposited in the body, it acts as a toxic substance to the human body. In recent years, fine dust introduced from China is increasing significantly, the size of PM2.5 is less than about $1 / 20$ of the pores, and currently $80 \%$ of the world's population is

Received: August 18, 2020 / Revised: August 31, 2020 / Accepted: September 3, 2020

* Professor.

${ }^{\dagger}$ Corresponding author: Kyung-Yae Hyun. Department of Clinical Laboratory Science, Dong-Eui University, Busan 47340, Korea. Tel: +82-51-890-2683, Fax:+82-0505-182-6877, e-mail: kyhyun@deu.ac.kr

(C) The Korean Society for Biomedical Laboratory Sciences. All rights reserved.

(C) This is an Open Access article distributed under the terms of the Creative Commons Attribution Non-Commercial License (http://creativecommons.org/licenses/by-nc/3.0/) which permits unrestricted non-commercial use, distribution, and reproduction in any medium, provided the original work is properly cited. 
exposed to PM2.5, increasing its severity.

The risk of ultrafine dust containing heavy metals such as lead and cadmium and various chemicals (Kim et al., 2016) weakens the metabolism of the skin, resulting in sebum. It decreases the control function and causes itching, dryness, and skin problems. Harmful substances such as heavy metals and environmental hormones contained in PM promote the secretion of inflammatory cytokines in cells and increase the number of white blood cells to exacerbate atopic dermatitis that causes allergic reactions.

PM produces a lot of free radicals, which are toxic substances in the human body, and these free radicals destroy collagen in the skin, reducing skin elasticity, causing exogenous aging (Lecal et al., 2016). In particular, the skin acts as a barrier between the organism and the environment because it is located on the outermost part of our body in direct contact with fine dust, and these barrier functions are degraded with frequent exposure to contamination. Therefore, from a cosmetic point of view, the demand for fine dust is increasing, but research on preventing skin contamination is still insufficient.

Nypa fruticans Wurmb (NF) used in this study is a plant that has traditionally been used for toothaches because of its excellent antibacterial activity in Southeast Asia, and has been recently imported to Korea (Prasad et al., 2013). According to previous reports, it has been reported that NF contain a large amount of phenolic acid and flavonoids, and have excellent antioxidant and cholesterol inhibitory effects (Yusoff et al., 2015). As material sources of natural medicine in oriental countries, most of those medicinal effects of Codium fragile (CF) and Enteromorpha compressa (EC) are directly or indirectly related to anti-inflammatory action of the seaweed (Kang et al., 2012). Saussurea neoserrata (SN) is a natural substance that has an effect on detoxification and is expected to help prevent adsorption or discharge of sulfur oxides and nitrogen oxides in PM.

In this study, the possibility of anti-pollution cosmetic material was investigated by measuring the inhibitory effect of free radicals using NF, SN, CF and EC, which has antiinflammatory and antioxidant effects against irritation caused by dust.

\section{MATERIALS AND METHODS}

\section{Preparation of samples}

The dust PM1648a used in this study is urban particulate matter and was purchased from the National Institute of Standards and Technology (NIST; Gaithersburg, MD, USA). It has an average particle size of $5.85 \mu \mathrm{m}$. NF and SN were purchased from Todipalm Korea (Korea) and Eco Plaza (Korea), respectively. CF and EC were provided in a mixture form by Kangs kosmetik (Korea). NF and SN were immersed in the distilled water at a sample : solvent ratio of 1:20 (w/v) for $24 \mathrm{~h}$ at $60^{\circ} \mathrm{C}$. The mixtures were then homogenized at $60^{\circ} \mathrm{C}$ for $4 \mathrm{~h}$ using a homogenizer (IKA, Staufen, Germany). The extracts were then filtered using the filter paper, concentrated at $60^{\circ} \mathrm{C}$ using a rotary evaporator (IKA) and freezedried for $24 \mathrm{~h}$. All freeze-dried extracts were stored at $4{ }^{\circ} \mathrm{C}$ prior to further experiments. All experiments were repeated in triplicate.

\section{Reagents and instruments}

Ascorbic acid, dimethyl sulfoxide (DMSO), methanol and 3-(4,5-dimethylthiaso-2-yl)-2,5-di Phenyl tetrazolium bromide (MTT) is Sigma-Aldrich, St. Louis (MI, USA). 1\% antibiotic antifungal antibiotics, $10 \%$ fetal bovine serum (FBS), phosphate buffered saline (PBS), Dulbecco's Modified Eagle's Medium (DMEM) was purchased from Gibco (Thermo Fisher Scientific, Inc., Waltham, MA, USA) for cell culture. The $\mathrm{CO}_{2}$ incubator was purchased from Thermofisher Scientific (Waltham, MA, USA). Microplate reader (Bio-Rad Laboratories, Inc., Hercules, CA, USA) Was used in measures the absorbance of the Prostaglandin $\mathrm{E}_{2}\left(\mathrm{PGE}_{2}\right)$ ELISA assay kit (R\&D system, Minneapolis, Minnesota, USA) and the non-radioactive cytotoxicity assay kit (Promega, Madison, WI, USA). To measure the concentration of free radicals in cells with dichlorofluorescin diacetate (DCFDA; Thermofisher Scientific), fluorescence intensity was measured using a Flourescence reader (Molecular Devices, San Joes, CA, USA).

\section{Cell line and culture}

Human keratinocytes (Human adult low calcium high 
temperature: $\mathrm{HaCaT}$ ) cells used in this experiment were presold by the Korean Cell Line Bank, and DMEM medium containing $1 \%$ antibiotic antifungal and $10 \%$ FBS was used. Incubated in a $\mathrm{CO}_{2}$ incubator adjusted to $37^{\circ} \mathrm{C}, 5 \% \mathrm{CO}_{2}$.

\section{Cell viability measurement (MTT analysis)}

MTT assay was performed to measure the effect of the sample on cell growth. Living cells with active metabolism reduce water-soluble yellow 3-(4,5-dimethylthiaso-2-yl)-2,5diphenyltetrazolium bromide by the action of intracellular mitochondrial dehydrogenase, resulting in a purple insoluble form. HaCaT cells were placed in a 96-well plate of $1.0 \times$ $10^{4}$ cells/mL using DMEM medium supplemented with $10 \%$ FBS and cultured for 18 hours, and then the four mixtures were concentrated and cultured for 24 hours. Then, $50 \mu \mathrm{L}$ of MTT solution was added and reacted for 4 hours. After the culture was completely removed and washed with PBS, $200 \mu \mathrm{L}$ of DMSO was added to completely dissolve the precipitate, and the absorbance was measured at $540 \mathrm{~nm}$ using a microplate reader (Ha, 2014). The average absorbance value for each sample group was obtained, compared with the absorbance value of the control group to evaluate the cell growth rate, and then repeated three times.

\section{Measurement of inflammation effect by fine particles}

Inflammation expression effect by particulate PM1648a was measured by a $\mathrm{PGE}_{2}$ expression effect test (Kim et al., 2009; Park and Son, 2011). Raw264.7 cells were inoculated into a 48-well plate (SPL, Korea) at $1 \times 10^{5}$ cells/well, cultured for 18 hours, and then PM1648a were treated by concentration and cultured for 24 hours. Before collecting the culture medium, the control cells were treated with $1 \mathrm{x}$ lysis buffer (Promega) and incubated for 45 minutes, and then the culture medium was centrifuged at 3,000 rpm for 5 minutes. The obtained supernatant was measured for the amount of $\mathrm{PGE}_{2}$ expression using a $\mathrm{PGE}_{2}$ ELISA assay kit (R\&D system), and the experiment was repeated three times. All samples were stored frozen below $-20^{\circ} \mathrm{C}$ until quantified.

\section{Measurement of intracellular antioxidant effect (change in active oxygen concentration)}

The change in the concentration of free radicals in cells was measured using the DCF-DA of the fluorescent probe. DCF-DA, a non-fluorescent substance, is oxidized by reactive oxygen species (ROS) when hydrogen peroxide-related peroxide is present in the cell, resulting in green fluorescence. Therefore, ROS can be measured via DCF-DA. $1 \times 10^{4}$ HaCaT cells were inoculated into a 96-well plate (SPL) and cultured for 18 hours. Four mixed concentrations and PM1648a were simultaneously treated and cultured for 24 hours. When incubation is complete, remove the medium and wash twice with PBS. After $10 \mu \mathrm{M}$ DCF-DA was added to each well and incubated for $90 \mathrm{~min}$ in an incubator at $37^{\circ} \mathrm{C}$ and $5 \% \mathrm{CO}_{2}$, fluorescence intensities were measured at excitation $485 \mathrm{~nm}$ and emission $530 \mathrm{~nm}$ using a fluorescence reader.

\section{Statistical processing}

Measurement data was performed with a paired $t$-test, and it was confirmed that there was a statistically significant difference when the significance probability $P<0.05$ in the 95\% confidence interval.

\section{RESULTS}

\section{Cell viability (MTT assay)}

$\mathrm{HaCaT}$ cells were treated with the mixture at different concentrations to confirm cell viability. A mixture of NF, SN, $\mathrm{CF}$ and EC was treated at a concentration of $0.0125 \mathrm{mg} /$ $\mathrm{mL}$ to $2 \mathrm{mg} / \mathrm{mL}$ to confirm cell viability (Fig. 1). Overall, the cell viability gradually decreased in a concentrationdependent manner, but showed a cell viability of $90 \%$ or more up to a concentration of $2 \mathrm{mg} / \mathrm{mL}$.

\section{Inflammation expression effect by microparticles}

For the microparticle PM1648a, the concentration was increased to $0,6.25,12.5,50,100 \mu \mathrm{g} / \mathrm{mL}$ for each concentration, and the expression level of $\mathrm{PGE}_{2}$, an inflammatory substance, was measured (Fig. 2). It was found that the $\mathrm{PGE}_{2}$ expression level increased significantly from the concentration of PM1648a of the microparticles above $6.25 \mu \mathrm{g} /$ $\mathrm{mL}$, and a significant effect of inflammation expression was exhibited at the concentration of 12.5, 25, 50 and $100 \mu \mathrm{g} / \mathrm{mL}$ of the dust. Since the maximum $\mathrm{PGE}_{2}$ expression level was 


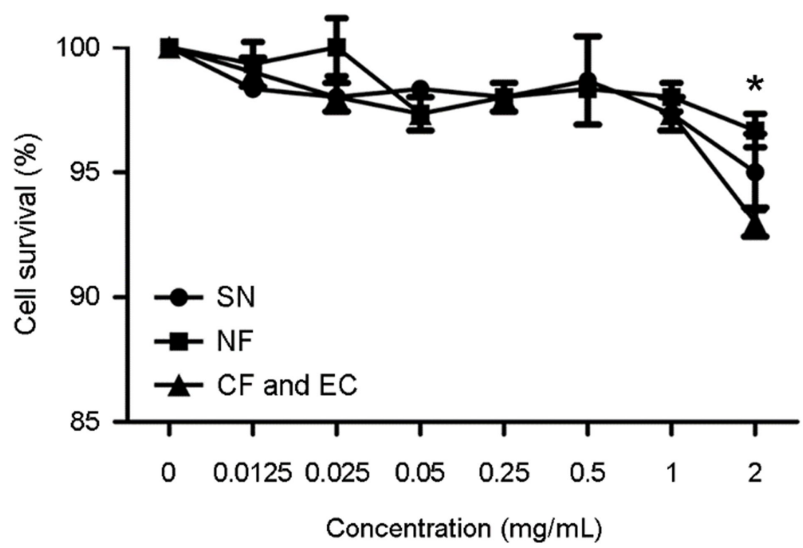

Fig. 1. Viability of HaCaT cells according to the concentration of the complex using MTT assay. Bars represent the mean \pm SD of triplicate measurements. ${ }^{*} P<0.05$, compared to the control group.

displayed at a concentration of $25 \mu \mathrm{g} / \mathrm{mL}$, the concentration of inflammation expression by microparticles was determined to be $25 \mu \mathrm{g} / \mathrm{mL}$.

\section{Inflammation inhibition effect by fine particles}

In order to observe the anti-inflammatory effect of natural products using $\mathrm{PGE}_{2}$ expression, the control group was stimulated with $25 \mu \mathrm{g} / \mathrm{mL}$ of PM1648a, and the experimental group was treated with $25 \mu \mathrm{g} / \mathrm{mL}$ of PM1648a and a mixture of NF, SN, CF and EC at the same time. And then after incubation for 24 hours, the inhibitory activity of $\mathrm{PGE}_{2}$ production was confirmed (Fig. 3). In addition, in the case of the mixed extract, a synergistic effect of inhibiting antiinflammatory activity was confirmed in the mixed composition of $(\mathrm{NF}: \mathrm{SN}=1: 1)$ or $(\mathrm{NF}: \mathrm{CF}: \mathrm{EC}=1: 0.3: 0.3)$. Through this, it can be understood that in the case of the above extract, when a specific composition is mixed within a specific range, a synergistic effect according to the interaction is exerted, thereby increasing the resistance activity against each harmful substance.

\section{ROS production inhibition (DCF-DA assay)}

In order to measure the change in active oxygen concentration in cells using DCF-DA assay, the control group was stimulated with $25 \mu \mathrm{g} / \mathrm{mL}$ of PM1648a to HaCaT cells, and the experimental group was treated with $25 \mu \mathrm{g} / \mathrm{mL}$ of PM1648a and a mixture of NF, SN, CF and EC at the same

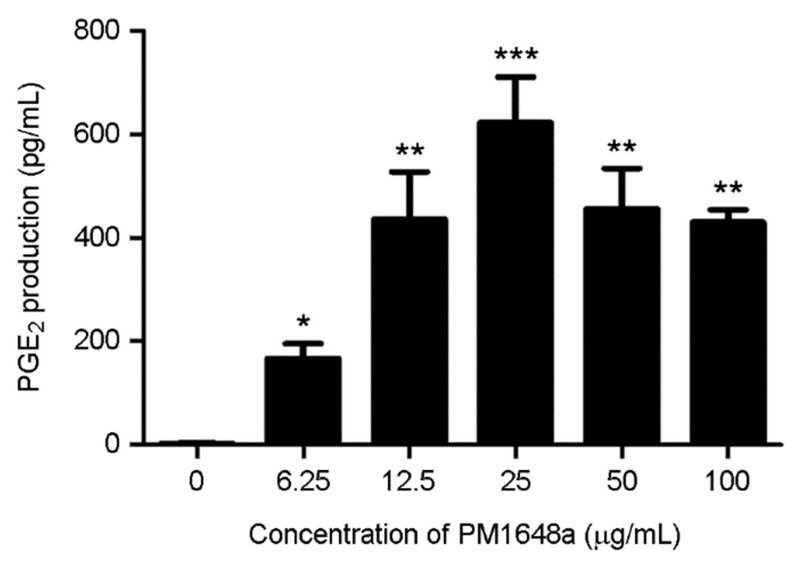

Fig. 2. $\mathrm{PGE}_{2}$ production from $\mathrm{HaCaT}$ cells stimulated with the PM1648a. Bars represent the mean \pm SD of triplicate measurements. $* P<0.05,{ }^{* *} P<0.01,{ }^{* * *} P<0.001$ compared to the 0 concentration of the PM1648a.

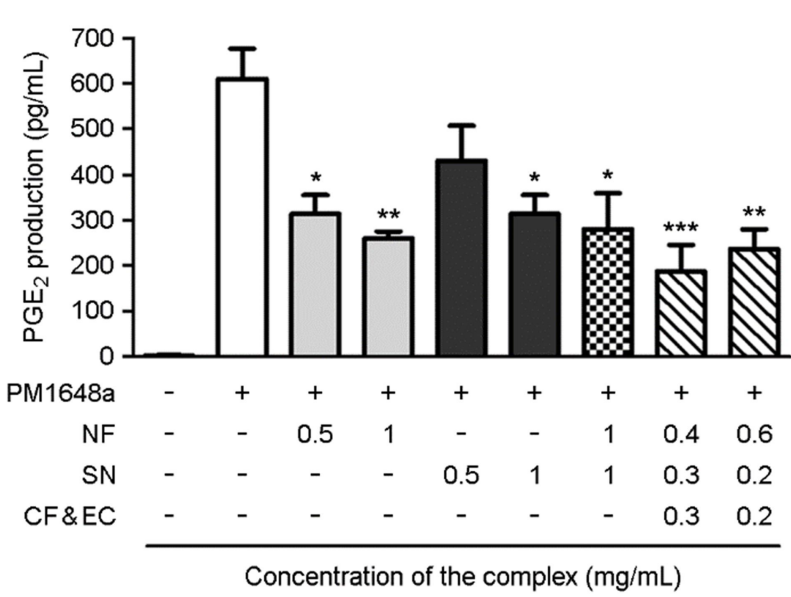

Fig. 3. $\mathrm{PGE}_{2}$ production from $\mathrm{HaCaT}$ cells stimulated with $\mathrm{PM} 1648 \mathrm{a}$ $(25 \mu \mathrm{g} / \mathrm{mL})$ according to the concentration of the complex. Bars represent the mean \pm SD of triplicate measurements. $* P<0.05$, $* * P<0.01, * * * P<0.001$, compared to the control group.

time. And then after incubation for 90 minutes, ROS production inhibitory activity was confirmed (Fig. 4). In the case of a single extract, NF had the best anti-pollution effect in the inhibitory effect of active oxygen production. In the case of SN, it can be seen that the effect is almost similar to that of NF. On the other hand, in the case of the mixed extract, a synergistic effect of inhibiting the production of active oxygen was confirmed in the mixed composition of (NF:SN $=1: 1)$ or $(\mathrm{NF}: \mathrm{CF}: \mathrm{EC}=1: 0.3: 0.3)$. 


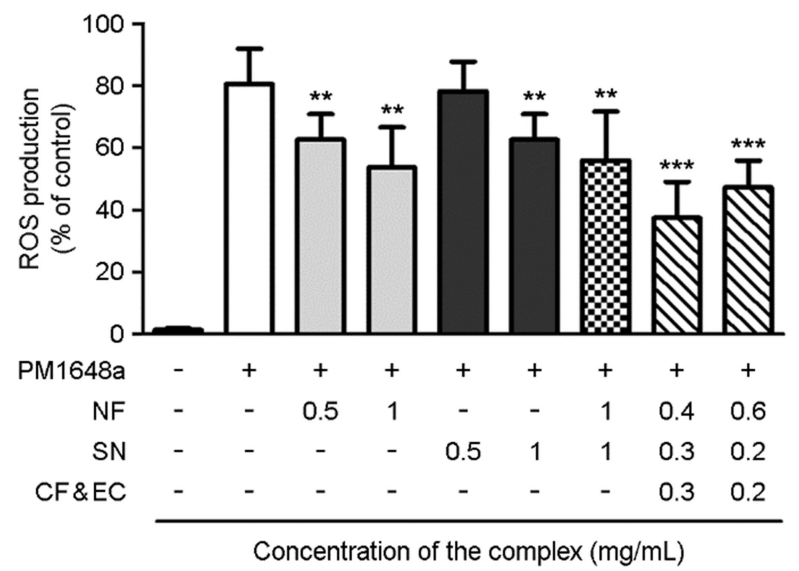

Fig. 4. ROS production from $\mathrm{HaCaT}$ cells stimulated with PM1648a $(25 \mu \mathrm{g} / \mathrm{mL}$ ) according to the concentration of the complex. Bars represent the mean $\pm \mathrm{SD}$ of triplicate measurements. ${ }^{* *} P<0.01$, $* * * P<0.001$, compared to the control group.

\section{DISCUSSION}

PMs are mixtures of particles suspended in the air (Kim et al., 2016; Jina et al., 2018). Since PM is a mixture of insoluble particles and soluble components such as gases or ions, even if the particles cannot penetrate the skin, they can cause harmful effects through soluble components (Guarnieri and Balmes, 2014; Beelen et al., 2008; Castano-Vinyals et al., 2008). Nevertheless, since there is no direct evidence as to whether the particles can penetrate the skin, we tried to determine if the locally collected PM particles trigger inflammation through a ROS dependent manner. In addition, since atopic dermatitis is a representative disease of damaged skin barrier, the influence of inflammatory mediators on PM penetration was also investigated. It also aims to explore natural substances that regulate it.

In this study, dust was reviewed on PM1648a (urban particulate) purchased from the National Institute of Standards and Technology. Comparing the effects of each treatment condition in each experiment, NF had the best anti-pollution effect in the case of a single extract in the inhibitory effect of active oxygen production. In addition, in the case of the extract used in this study, it was confirmed that when a specific composition is mixed within a specific range, a synergistic effect according to the interaction appears. Combining the experimental results of a mixture of NF, SN, CF and EC by induction of the dust stimulation, this mixed extract has an effective effect on cell viability (MTT), and is effective against fine dust stimulation. Inhibition of inflammatory factors $\left(\mathrm{PGE}_{2}\right)$ and intracellular free radicals (ROS) by inhibiting effects were also significant, indicating the possibility of use as anti-pollution cosmetics.

Several scientific studies have shown that prolonged exposure to environmental pollutants can modify biochemical parameters in human skin, impair barrier function, and promote skin aging mechanisms. The visible consequences of these effects are dryness, wrinkles, black spots and worsening skin sensitivity. As awareness of the effects of environmental stressors on the skin is increasing, consumer demand for cosmetics that can provide anti-pollution effects is increasing. A number of recent studies have studied the antioxidant effect obtained from natural extracts (Fletcher et al., 2011; Piao et al., 2011; Mocan et al., 2016). In fact, plant extracts are often rich in bioactive compounds whose activity (antioxidants, chelating, film-forming) can be utilized in antipollution formulations.

Most of the studies describe the anti-fine dust effect by inhibiting the generation of free radicals, similar to the conclusions in this study (Anonymous, 2011; Prusakiewicz et al., 2006). As an indicator, it was confirmed by the level of malonyldialdehyde, a process of lipid peroxidation, and showed higher lipid antioxidant activity than vitamin E. Therefore, in future studies, we will study the related inhibition mechanisms in detail.

As mentioned above, airborne pollutants adversely affect human skin mainly through oxidative damage, resulting in oxidative stress and depletion of oxidative enzymes and other antioxidants in the epidermis. For this reason, it is not surprising that most plants used as sources of anti-pollution cosmetic ingredients contain antioxidants as active substances. In our highly industrialized and chemically polluted world, it is not surprising that most plants used as sources of antipollution cosmetic ingredients contain antioxidants as active substances.

The anti-pollutant used in our study consisting of NF, SN, $\mathrm{CF}$ and $\mathrm{EC}$ extracts is a very promising functional products because of the antioxidant and anti-inflammation effects attributed to each ingredient along with our findings. Considering 
our results, it can be suggested that this anti-pollutant consisting of NF, SN, CF and EC may be a good ingredient for skincare products for the cosmetic industry due to their antioxidant properties, which may especially alter skin aging.

\section{Abbreviations}

PM - Particulate matters, NF - Nypa fruticans Wurmb, $\mathrm{SN}$ - Saussurea neoserrata, CF - Codium fragile, EC Enteromorpha compressa, DMSO - dimethyl sulfoxide, MTT - 3-(4,5-dimethylthiaso-2-yl)-2,5-di Phenyl tetrazolium bromide, FBS - fetal bovine serum, PBS - phosphate buffered saline, DMEM - Dulbecco's Modified Eagle's Medium, $\mathrm{PGE}_{2}$ - Prostaglandin $\mathrm{E}_{2}$, DCF-DA - Dichlorofluorescin diacetate, HaCaT - Human adult low calcium high temperature, ROS - reactive oxygen species

\section{ACKNOWLEDGEMENT}

This work was supported by the Busan Innovation Institute of Industry, Science \& Technology Planning (BISTEP) grant funded by the Busan Metropolitan City (Project: Open Laboratory Operational Business Developing and Diffusing the Regional Specialization Technology).

\section{CONFLICT OF INTEREST}

The authors declare that they have no conflict of interest.

\section{REFERENCES}

Anonymous. Bioavailable Polyphenols for Anti-Ageing Cosmetics. Personal Care Magazine Online. 2011. Available online: https:// www.personalcaremagazine.com/story/8392/bioavailablepolyphenols-for-anti-ageing-cosmetics.

Beelen R, Hoek G, van den Brandt PA, Goldbohm RA, Fischer P, Schouten LJ, Armstrong B, Brunekreef B. Long-term exposure to traffic-related air pollution and lung cancer risk. Epidemiology. 2008. 19: 702-710.

Castano-Vinyals G, Cantor KP, Malats N, Tardon A, Garcia-Closas R, Serra C, Carrato A, Rothman N, Vermeulen R, Silverman D, Dosemeci M, Kogevinas M. Air pollution and risk of urinary bladder cancer in a case-control study in Spain. Occup Environ Med. 2008. 65: 56-60.

Fletcher JN, Kinghorn AD, Slack JP, Scott McCluskey T, Odley A, Jia Z. In vitro evaluation of flavonoids from Eriodictyon californicum for antagonist activity against the bitterness receptor hTAS2R31. J Agric Food Chem. 2011. 59: 13117-13121.

Guarnieri M, Balmes JR. Outdoor air pollution and asthma. Lancet. 2014. 383: 1581-1592.

Ha HY. The effects of water extract from Dictamnus dasycarpus Turcz on hepatocellular damage In vitro. Kor J Herbology. 2014. 29: 91-95.

Jina SP, Lia Z, Choi EK, Lee S, Kim YK, Seo EY, Chung JH, Cho $S$. Urban particulate matter in air pollution penetrates into the barrier-disrupted skin and produces ROS-dependent cutaneous inflammatory response in vivo. J Dermatol Sci. 2018. 91: 175-183.

Kang CH, Choi YH, Park SY, Kim GY. Anti-inflammatory effects of methanol extract of Codium fragile in lipopolysaccharidestimulated RAW 264.7 cells. J Med Food. 2012. 15: 44-50.

Kim DH, Park SJ, Jung JY, Kim SC, Byun SH. Anti-inflammatory effects of the aqueous extract of Hwangnyeonhaedok-tang in LPS-activated macrophage cells. Korean J Herbology. 2009. 24: 39-47.

Kim KE, Cho D, Park HJ. Air pollution and skin diseases: Adverse effects of airborne particulate matter on various skin diseases. Life Sci. 2016. 152: 126-134.

Lecal S, Boursier E, Fitoussi R, Vié K, Momas I, Seta N, Achard S. In vitro model adapted to the study of skin ageing induced by air pollution. Toxicol Lett. 2016. 259: 60-68.

Mocan A, Schafberg M, Crisan G, Rohn S. Determination of lignans and phenolic components of Schisandra chinensis (Turcz.) Baill. Using HPLC-ESI-ToF-MS and HPLC-online TEAC: Contribution of individual components to overall antioxidant activity and comparison with traditional antioxidant assays. J Funct Foods. 2016. 24: 579-594.

Park SC, Son DY. Mediator by LPS-stimulated raw 264.7 macrophages. J Korean Soc Food Sci Nutr. 2011. 40: 486-492.

Pan TL, Wang PW, Aljuffali IA, Huang CT, Lee CW, Fang JY. The impact of urban particulate pollution on skin barrier function and the subsequent drug absorption. J Dermatol Sci. 2015. 78: 51-60.

Piao MI, Yoo ES, Koh YS, Kang HK, Kim J, Kim YJ, Kang HH, Hyun JW. Antioxidant effects of the ethanol extracts from flower of Camellia japonica via scavenging of reactive oxygen species and induction of antioxidant enzymes. Int J Mol Sci. 2011. 12: 2618-2630.

Prasad N, Yang B, Kong KW, Khoo HE, Sun J, Azlan A, Ismail A, Romli ZB. Phytochemicals and Antioxidant Capacity from Nypa fruticans Wurmb. Fruit Evid-Based Compl A. 2013. 
2013: 154606.

Prusakiewicz J, Ackerman C, Voorman R. Comparison of skin esterase activities from different species. Pharm Res. 2006. 23: $1517-1524$

Yusoff NA, Ahmad M, Al-Hindi B, Widyawati T, Yam MF, Mahmud R, Razk KN, Asmawi MZ. Aqueous Extract of Nypa fruticans Wurmb. Vinegar Alleviates Postprandial Hyperglycemia in Normoglycemic Rats. Nutrients. 2015. 7: 7012-7026.
https://doi.org/10.15616/BSL.2020.26.3.157

Cite this article as: Choi GE, Lee GH, Hyun KY. Antioxidant and Anti-pollution Composition Containing the Extract of Nypa fruticans Wurmb, Saussurea neoserrata, Codium fragile and Enteromorpha compressa. Biomedical Science Letters. 2020. 26: 157-163. 